\title{
Dimensions and indicators of non-profit financial condition: Evidence from South African public universities
}

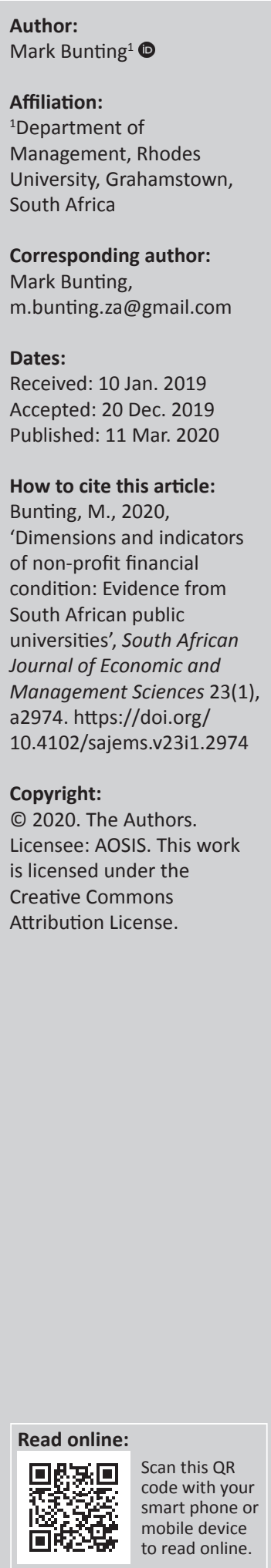

Background: More than three decades of research have failed to achieve convergence on a method for the measurement of non-profit financial condition, with the literature reporting a bewildering array of financial dimensions, and more than 100 ratios and indicators.

Aim: This article offers a contribution to a broader discourse in non-profit financial analysis by recognising, and taking action in response to, the potential threat to research validity arising from the generally unchallenged presumption that accounting numbers provide a complete, unbiased and error-free representation of an entity's underlying economic reality.

Setting: The 23 South African public universities in continuous existence for the 10 financial years from 01 January 2007 to 31 December 2016.

Methods: From the non-profit financial analysis literature, three foundational models are identified, and 24 associated ratios are specified as candidate indicators of financial condition. These are calculated for each university from accounting numbers which have been adjusted in mitigation of inadequacies of the financial reporting rules. Principal component analysis is applied to evaluate the indicators, and eliminate those which lack significant association with the emergent dimensionality of financial condition.

Results: The financial condition of South African public universities is positively associated with liquid discretionary financial assets, which are interpreted as representative of financial resilience and defensive capacity in the presence of economic shock. Unrestricted equity has incremental relevance, suggesting that the universities derive financial benefits from a capital structure in which assets are funded through sources that are burdened with neither debt obligations nor donor restrictions.

Conclusion: This research appears to be among the first to propose a dimensionality for non-profit financial condition that is developed on a foundation of responding to the need for mitigation of inadequacies in the financial reporting system.

Keywords: Non-profit financial condition; university financial health; Higher education finance.

\section{Introduction}

Although South African public universities are subject to state oversight and steering (South Africa 1997), they are not directly state-owned. Each university is constituted under its own private statute (South Africa 2002), which confers substantial independent decision-making capacity upon council, senate, management, students, and other stakeholders. Furthermore, even though South African universities in 2007-2016 received an average of $46 \%$ of their revenues from conditional state transfers, this still means that the majority of their income is derived from private sources. In addition, the regulatory context (South Africa 2014) requires that the universities report under International Financial Reporting Standards, not public sector accounting rules, and that they are to be scrutinised by private sector audit firms, not the Auditor-General's office. Despite their descriptive title, therefore, there are important differences between South African public universities and the municipalities, provincial authorities, and government departments which are clearly identifiable as state agencies.

The universities also exist within an economic frame of reference that is significantly different from that which applies to companies and other business enterprises. One of the key theoretical elements underpinning such entities is their owners' expectation that they will receive future dividends. Another is the existence of a profit-maximising production function. Neither of these 
economic conditions applies to the South African public universities, which have no shareholders, and which exist in order to achieve social outcomes, not to generate profit.

The universities examined in this article are therefore members of neither the governmental nor the private sectors of the South African economy. Instead, they exist within a third economic partition, known as the non-profit sector. Hansmann (1980:838) defines a non-profit entity as one that 'is barred from distributing its net earnings, if any, to individuals who exercise control over it.' It is this formal condition, generally referred to as the non-distribution constraint, that has emerged as the seminal defining characteristic of the non-profit organisation. The dominance of this definition over an earlier one focused on mission (Newhouse 1970) is, perhaps, less unexpected when considered against the pervasive existence of mission statements across all parts of the economy, including public and private sectors.

Weisbrod, Ballou and Asch (2008:2) describe the operational and financial context of the university as a two-good framework in which it is obliged simultaneously to pursue 'both lofty social missions and crass money-making activities.' Primacy of mission and the absence of a profitmaking motive do not, therefore, mean that the universities are able to ignore financial concerns, which exist as pivotal enablers - or inhibitors - of institutional mission, thus explaining an enduring academic and practitioner interest in identifying defensible and decision-useful indicators of nonprofit financial health.

In a commercial context, a number of approaches are available for the evaluation of financial condition. Firstly, there is broad consensus (as in, for example, Penman 2013) that the relevant financial dimensions of a commercial operation are its liquidity, solvency, profitability, and efficiency. Secondly, there exists a family of methodologies for valuing the ownership interest of a business (Feltham \& Ohlson 1995; Ou \& Penman 1989). Thirdly, there is a corporate failureprediction group of models derived from Altman (1968) and Ohlson (1980). These analytical approaches necessarily accord prominence to matters such as profitability and the valuation of shares or bonds, and it is therefore unsurprising that they have proven not to be directly transportable into a non-profit environment.

Chabotar (1989) represents one of the first attempts at bridging the divide between commercial and non-profit financial analysis, arguing that the universality of financial management concerns is such that a commercially styled analysis is equally suitable for the non-profit sector. Tuckman and Chang (1991) disagree, and are more influential, identifying four specialised indicators for use in the evaluation of non-profit financial vulnerability.

One thread of subsequent research (Greenlee \& Trussel 2000; Hager 2001; Parsons \& Trussel 2009; Trussel 2002; Trussel \& Greenlee 2004) applies multivariate analyses in order to add methodological rigour to the essentially descriptive
Tuckman-Chang framework. Their results are, however, inconclusive, generally finding support for only subsets of the original four indicators, as well as evidence of variability in their significance across different types of non-profit entity.

Other researchers explore alternative avenues. Chu et al. (1991), Prentice (2016), Ritchie and Kolodinsky (2003), Trussel and Parsons (2008), Watkins (2000), and Zeller, Stanko and Cleverley (1996) apply factor analysis to identify a variety of non-profit financial performance factors, each with a different set of associated ratios, none of which is completely congruent with the Tuckman-Chang formulation. Kingma (1993) adapts modern portfolio theory to model revenue interactions in the non-profit sector, finding neither theoretical nor empirical support for the Tuckman-Chang income diversity indicator. Tinkelman and Donabedian (2007) propose an alternative four-factor framework for the decomposition of a non-profit entity's financial performance that is inspired by the DuPont analysis of return on equity. Bowman (2011:39) asserts that his framework 'represents the first comprehensive alternative in 20 years to the Tuckman-Chang model.'

In summary, almost three decades of research have failed to achieve either conclusive support for the Tuckman-Chang construct or convergence on an alternative model, with the literature reporting a bewildering array of dozens of financial dimensions, and more than 100 ratios and indicators. The situation suggests that there is much that we still do not know about non-profit financial condition. Although it might seem implausible that this study's consideration of a small population of South African universities would have anything incremental to offer such a discourse, there are at least three potentially interesting ways in which this research differs from that which has come before. Firstly, this article differs from established methodology in non-profit financial research in that no financial database exists for the organisational population of interest. Although the absence of a database is not, of itself, especially significant, the fact that the data require manual retrieval provides an important opportunity. Chang and Tuckman (2010) and Mitchell (2017) draw attention to pervasive evidence of serious errors, omissions, and misallocations in the databases commonly used in large population non-profit research. A response to this concern is offered by this study's use of accounting data which were collected by hand from, and rigorously cross-checked against, primary sources with a reasonable presumption of reliability (being the institutions' audited financial statements).

Secondly, Robinson et al. (2009) and White, Sondhi and Fried (2003), among others, demonstrate the need to reformulate and repair accounting data in order to achieve optimal levels of representational validity and decision-usefulness. Such corrections and adjustments are made in none of the large database studies cited above. In contrast, this article provides a detailed account of the deficiencies (both systemic and institution-specific) in the universities' financial reports and makes the necessary adjustments to the data in order to 
mitigate inadequacies of comparability and correspondence with economic reality. The possibility that the lack of consensus on the defining characteristics of non-profit financial condition may (at least partially) be attributable to data errors and accounting problems remains unexplored in the international literature. By carrying out error-checking that goes substantially further than, say, a crude winsorising of the data, and by paying careful attention to the idiosyncratic consequences of the accounting rules, this article therefore carries at least some potential for shedding light on the matter.

Thirdly, this article offers a contribution to a South African frame of reference which is characterised by an absence of comparably comprehensive academic studies of university financial health. Admittedly, these institutions have not been ignored in the literature, but by far the dominant line of financial enquiry has been directed specifically at the state subsidy mechanism, with De Villiers and Steyn (2009) appropriately representative of the genre. (A rather lesser number of studies consider other isolated aspects of South African university finances, such as Wangenge-Ouma 2012, on tuition fees.) Furthermore, the practitioner space is characterised by a large number of competing narratives of South African university financial condition, including most notably the annual financial reviews prepared by university management structures (using self-selected and nonstandard ratio sets), and the annual reports of Statistics South Africa (based on an opaque methodology involving cash-based numbers of unknown provenance which defy reconciliation with the universities' accrual-basis audited financial statements).

Among the many available academic and practitioner considerations of non-profit financial condition, three are selected as appropriate sources of indicators for this research. In recognition of its historical persistence, the first of these is the Tuckman and Chang (1991) framework. Although this approach has faced accumulating challenges to its suitability as a unified non-profit financial analysis mechanism, there still exists a measure of support for its ratios, when considered individually. For reasons of practitioner relevance, the second source of indicators is KPMG (2010), a model created specifically for universities. Although focused on the United States, it has been applied outside this context, including Europe and Australia, and some of its ratios appear in a recent review of South African university financial health (PricewaterhouseCoopers 2014). The KPMG model adopts a normative approach, and the specification of its various benchmarks is obviously dependent on economic context. However, this study imports none of the foreign baselines, making use only of the ratios themselves. Furthermore, it is reasonable to suppose that the authors, as experienced audit and advisory professionals, may have an interesting perspective to offer those who are concerned with financial analysis in the higher education sector. Finally, Bowman (2011) explicitly positions his study as a challenge to the Tuckman-Chang model, and proposes a number of questions for future research. Most of these have yet to be addressed in the literature, and the current study offers one response, by including in its consideration the Bowman indicators of non-profit financial capacity and sustainability.

The remainder of this article proceeds as follows. From the three foundational models, a set of 24 indicators is identified, each indicative of an expectation about the relevance of a particular financial characteristic of the universities to a consideration of its financial condition. In the section on data and method, an explanation is provided of the standardisation adjustments made to the accounting numbers, following which the analytical techniques of this study are described. These methods are applied in order to identify a parsimonious set of non-profit financial indicators that satisfactorily explains the data set's total variability, as well as the institutional financial dimensions with which those indicators are most closely associated.

Subsequent to this, the results of these procedures are reported and discussed. More than half of the proposed ratios are eliminated on the basis that they are found not to provide a usefully incremental contribution to the financial evaluation of the universities. The remaining indicators are shown to be closely associated with relative measures of the universities' expendable resources, as well as their unrestricted equity. Evidence is presented that the consideration of the financial condition of the South African public universities appears to be dominated by liquid discretionary financial assets, the absence or availability of which may be indicative of institutional defensive capacity in the presence of financial shock. Unrestricted equity is also found to be relevant, suggesting that university financial condition is positively associated with a capital structure that funds institutional assets through sources that are burdened with neither debt obligations nor donor restrictions.

The article concludes with a discussion of its implications and limitations, and suggestions for future research.

\section{Dimensions of non-profit financial health and associated ratios}

Tuckman and Chang (1991) identify four indicators (see Table 1), all postulated as representative of institutional resilience to financial shock. Their first ratio measures equity adequacy (calculated as total equity divided by total revenue [TETR]) and is indicative of a university's ability to replace lost revenue by making use of reserves, as well as the

TABLE 1: Tuckman and Chang indicators.

\begin{tabular}{llll}
\hline Indicator & Numerator & Denominator & Financial dimension \\
\hline TETR & Total equity & Total revenue & $\begin{array}{l}\text { Equity sufficiency in context } \\
\text { of total annual revenue }\end{array}$ \\
CONC & $\sum_{i=1}^{n} R_{i}^{2} \S$ & Not applicable & Revenue concentration \\
OXTX & Operating expenses & Total expenses & Cost structure flexibility \\
TSTR & Total surplus & Total revenue & $\begin{array}{l}\text { Surplus sufficiency in context } \\
\text { of total annual revenue }\end{array}$ \\
\hline
\end{tabular}

$\S$, Revenue source $(i)$ / total revenue where $i$ is state, tuition, contracts, sales, residence fees, private gifts, investments, other income.

TETR, total equity divided by total revenue; CONC, revenue concentration; OXTX, operating expenses divided by total expenses; TSTR, total surplus to total revenues ratio. 
accessibility of supplemental funding from financial institutions (which, the authors argue, are likely to look more favourably upon a loan request from a university with a higher TETR ratio).

The second Tuckman-Chang indicator is revenue source concentration (CONC), which is measured using a Hirschman (1964) concentration index (calculation details are provided in Table 1). This is the only indicator in the current article that has the expectation of an inverse association with financial condition. A university with diversified revenue sources (and therefore a lower CONC indicator) is postulated to be less vulnerable to downturns, because negative events are unlikely to have uniform consequences across different revenue streams.

Thirdly, cost structure flexibility (measured as operating expenses divided by total expenses [OXTX]) is expected to exist for organisations that have the ability to engage in cost reduction when faced with financial shock. In the South African context of the current study, this ratio is operationalised as an indicator of the proportionate size of the university's non-staff costs, because an institution with higher salaries and wages will, all else being equal, have lower recourse to cost-cutting measures than one with lower proportionate financial exposure to its employees. Lastly, the total surplus to total revenues ratio (TSTR) is included on the basis that surplus is the source of all self-funded growth in the institution. Furthermore, surplus offers a margin of safety, should there be a decline in revenue, and a negative TSTR ratio is directly indicative of a decrease in the institution's financial resilience.

Only one of the KPMG (2010) ratios (total surplus to total revenue: TSTR) intersects with the Tuckman-Chang set. Three of the remaining indicators (see Table 2) are scaled measures of expendable assets, defined as those that are both liquid and unrestricted. Infrastructure (fixed) assets and restricted financial assets are not immediately available to management for discretionary funding of new projects or institutional expenses. These are therefore excluded from expendable assets, which are calculated as cash plus investments less restricted equity. The first two ratios evaluate the sufficiency of a university's liquid and unrestricted wealth in relation to its long-term obligations. They are calculated as expendable assets divided by either total debt or total liabilities (XATD or XATL, depending on relative exposure to financial institutions; in this study, both are included as a result of high variability in debt levels across the South African system). Similarly, the ratio of expendable assets to total expenses (XATX) evaluates the sufficiency of expendable assets in the short-term context of annual institutional expenses. Finally, long-term sustainability is measured on the basis of ongoing institutional ability to set aside sufficient resources, calculated as total surplus divided by total equity (TSTE).

Bowman (2011) presents four ratios (see Table 3), none of which appears in the Tuckman-Chang or KPMG models. All are positively associated with financial health, as follows. In the long term, financial capacity is dependent on the institution not being overexposed to debt and is therefore measured as the proportion of assets that have been funded through equity (total equity divided by total assets [TETA]). Long-term sustainability depends on organisational ability to maintain expenses at a lower level than income (thereby ensuring that equity increases over time) and is measured by the ratio of total surplus to total assets (TSTA). Turning attention to the short term, financial capacity is determined by the immediate availability of resources that are both liquid and unrestricted. Although these are the same expendable assets that appear in the KPMG framework, the Bowman ratio scales them more narrowly against those expenses that involve actual outflows of cash. Thus, XACX is calculated as expendable assets divided by cash expenses, being total expenses minus depreciation. Short-term sustainability focuses on capital preservation, measured by the ratio of unrestricted surplus to cash expenses (USCX).

Between them, the three financial health models therefore propose a total of 12 different ratios as being relevant to the determination of institutional financial health. However, in the specific setting of the current study, it is appropriate to evaluate the sufficiency of these particular ratios as a plausible candidate indicator set. Table 4 provides the context for this consideration, by tabulating descriptive statistics for

TABLE 2: KPMG indicators.

\begin{tabular}{llll}
\hline Indicator & Numerator & Denominator & Financial dimension \\
\hline XATD & Expendable assets & Total debt & Sufficiency of liquid unrestricted assets in context of debt exposure to financial institutions \\
XATL & Expendable assets & Total liabilities & As for XATD but includes all institutional obligations, including those to creditors and employees \\
XATX & Expendable assets & Total expenses & Sufficiency of liquid unrestricted assets in context of total annual expenses \\
TSTE & Total surplus & Total equity & Surplus sufficiency in context of total equity \\
\hline
\end{tabular}

XATD, expendable assets divided by total debt; XATL, expendable assets divided by total liabilities; XATX, expendable assets to total expenses; TSTE, total surplus divided by total equity.

TABLE 3: Bowman indicators.

\begin{tabular}{llll}
\hline Indicator & Numerator & Denominator & Financial dimension \\
\hline TETA & Total equity & Total assets & Equity sufficiency in context of total assets \\
TSTA & Total surplus & Total assets & Surplus sufficiency in context of total assets \\
XACX & Expendable assets & Cash expenses & Sufficiency of liquid unrestricted assets in context of total annual cash expenses \\
USCX & Unrestricted surplus & Cash expenses & Sufficiency of unrestricted surplus in context of total annual cash expenses \\
\hline
\end{tabular}

TETA, total equity divided by total assets; TSTA, total surplus to total assets; XACX, expendable assets divided by cash expenses; USCX, unrestricted surplus to cash expenses. 
TABLE 4: Descriptive statistics: South African universities 2007-2016 (common-size analysis).

\begin{tabular}{|c|c|c|c|c|c|c|}
\hline Variable & Mean & Median & Standard deviation & Minimum & Maximum & Coefficient of variation \\
\hline Cash and financial assets & 47.3 & 46.8 & 15.2 & 12.2 & 79.9 & 0.321 \\
\hline Unrestricted equity & 47.3 & 53.1 & 21.8 & -3.2 & 82.2 & 0.461 \\
\hline Restricted equity & 23.9 & 23.4 & 14.2 & 0.8 & 63.6 & 0.595 \\
\hline Total equity & 71.2 & 77.6 & 17.8 & 5.4 & 92.6 & 0.249 \\
\hline Total debt & 3.0 & 1.6 & 3.9 & 0.0 & 22.0 & 1.289 \\
\hline Total liabilities & 28.8 & 22.4 & 17.8 & 7.4 & 94.7 & 0.617 \\
\hline Student source revenue & 31.4 & 30.8 & 6.5 & 18.9 & 50.6 & 0.208 \\
\hline Investment returns & 6.6 & 5.5 & 5.0 & -7.4 & 28.0 & 0.769 \\
\hline Other third-stream revenue & 16.1 & 13.0 & 10.4 & 0.2 & 46.3 & 0.647 \\
\hline Staff costs & 54.7 & 54.8 & 7.2 & 30.2 & 87.2 & 0.131 \\
\hline Operating expenses & 45.3 & 45.2 & 7.2 & 12.8 & 69.8 & 0.158 \\
\hline Surplus & 12.7 & 12.6 & 11.2 & -38.7 & 73.5 & 0.883 \\
\hline
\end{tabular}

Note: For the common-size analysis, balance sheet items are presented as percentages of total capital and income statement items are presented as percentages of total revenue. The coefficient of variation is calculated as standard deviation divided by mean and is indicative of the relative dispersion of data points.

selected financial components across this study's full 230 university-year panel. (All data are from this study.)

The first concern relates to the existence of a restrictedunrestricted partition in the capital structure of all institutions in this study. A substantial proportion of South African universities' capital (2007-2016 mean: 23.9\%) exists under legally binding restrictions imposed by donors or funders, and is unavailable for at-will deployment by institutional management. Tuckman and Chang (1991) emphasise the importance of equity restrictions in the evaluation of financial resilience, but accord no further recognition to the matter in their final choice of ratios. Apart from the Bowman (2011) short-term sustainability indicator (USCX), the other two models similarly ignore the fundamental difference between restricted and unrestricted equity, and include only considerations of total equity and total surplus. Therefore, the applicable ratios are extended in order to provide incremental focus on the expected positive relationships between financial health and unrestricted equity (UE), unrestricted surplus (US), and unrestricted revenue (UR). In this manner, UETA, USTA, USUE, USUR, and UEUR are added as alternative versions of the relevant ratios in the three models.

Next, the short-term components of the existing ratios provide comparative measures of expenses in only two dimensions: cash and total. However, the South African universities' staff costs are the largest functional expense exposure, at an average of $54.7 \%$ of total revenues. Therefore, XAMX and USMX (expendable assets and unrestricted surplus, divided by employee expenses) are included and, for symmetry of expense analysis in the Bowman (2011) short-term dimension, the ratio of unrestricted surplus to total expenses (USTX) is added as a sustainability indicator.

This research finds clear evidence that some South African universities treat the financial reporting boundary between cash (including cash equivalents) and financial assets as porous, with a number of unexplained inter period reclassifications between the two asset categories. There are also obvious cross-sectional differences in institutional accounting policies and, as a result, this study considers cash, cash equivalents, and financial assets in combination. Defined in this manner, total investments (TI) is the largest asset category for the universities, with a 10 -year mean of $47.3 \%$ of total assets. The existence of spending restrictions on investments is given recognition in the three models, which all use expendable assets as the applicable numerator. However, this gives rise to a potential mismatch with some of the associated denominators, because the accounting system requires that expenses be reported as a combined total of restricted and unrestricted activities. Therefore, total investments is included as an alternative numerator for the cash, employee, and total expense ratios, thereby adding TICX, TIMX and TITX as plausibly relevant indicators. Finally, the relatively high coefficient of variation for investment returns as a ratio of total revenue (IRTR, at 0.769 the third highest in this study) suggests the appropriate inclusion of this indicator as an extension of the Tuckman and Chang (1991) consideration of financial flexibility.

\section{Data and method}

The audited annual financial statements for the entire population of 23 South African public universities in continuous existence for the 10 financial years from 01 January 2007 to 31 December 2016 were obtained from the institutions' websites or, when unpublished by the institution, from the South African Department of Higher Education and Training. The starting point for the data series was selected in order to allow for the passage of at least two stabilising years following a series of institution-level mergers and campus carve-outs which ended in 2005. These actions affected the majority of the South African universities and reduced the institutional population from 36 to 23 . Three newer institutions, all less than three years old in 2016, were excluded from the study.

Line items from the universities' financial statements were manually entered into classification cells in spreadsheet files created for this purpose. Cross-checking during the initial data capture process was reinforced by applying the natural articulation of financial statements to identify imbalances 
requiring investigation and resolution. All apparent data anomalies were traced back to the component accounting numbers and corrected or confirmed. Because all data were extracted from primary sources (audited financial statements) rather than secondary ones (financial databases), no outlier eliminations were made.

Attention was then turned to addressing limitations in the applicable financial reporting system. These arise from the availability of choice in accounting method (which degrades the comparability of the financial numbers), as well as functional flaws in the accounting rule set (which impair their correspondence with the relevant underlying economic phenomena).

Therefore, property, plant and equipment (PPE) were restated, where necessary, so that all physical assets are measured at depreciated historic cost. A number of South African universities apply a revaluation model, in terms of which PPE is recorded at amounts approximating fair value. There is a vexed academic, practitioner and regulatory debate concerning the relative usefulness and reliability of historic cost versus fair value information (see for example Cascino et al. 2013; Christensen \& Nikolaev 2013; Whittington 2008).

However, in this study, the decision to restore comparability through the uniform application of historic costs, rather than fair values, is an unavoidable one based on data availability: the accounting rules require those universities applying the revaluation model to provide additional disclosure of the counterfactual historical cost amounts, while the reverse requirement does not apply.

In South Africa, state funding for infrastructure development projects is commonly transferred to the recipient institution in advance. During the time that the related building work is incomplete, the unexpended amounts are reported in institutional balance sheets as deferred income. Most of the universities choose to treat this as a liability, although a few treat the item as equity. The appropriate classification is not directly addressed in the accounting standards. In such situations, best practice requires the universities to consider the fundamental definitions of liability and equity in the conceptual framework for financial reporting. For the purposes of this analysis, all deferred income balances are allocated to restricted equity, on the basis that such classification more accurately represents a situation in which the state has never made demands for the refund of infrastructure grant transfers.

Further adverse effects on comparability arise at the point of expenditure of infrastructure grants on PPE. One of the accounting alternatives allowed (and which is applied by a number of the universities) is the recognition of a reduced cost, net of the state grant, for the relevant asset. Application of this method to a building costing, for example R80 million entirely funded through a state transfer, results in the complete absence of the new building from the institution's balance sheet, because its deemed cost under the accounting rules is nil. For analytical purposes, this accounting outcome is repudiated as being devoid of meaning and its effects are, accordingly, reversed.

South African universities offer a variety of retirement benefits to their employees, including defined benefit plans, which include final-salary pension promises and postemployment medical plans. Until the end of the 2012 financial year (and therefore affecting 6 out of this study's 10 years), the accounting rules allowed a number of alternatives for calculating the related liability. Some of these methods involved only partial recognition of the liability, asserted to be appropriate on the basis of market volatility as well as the fundamental unknowability of the distant future. In general, financial analysts reject the assertion that the partial recognition of a defined benefit liability provides decisionuseful information and make the necessary adjustments to restore the measurement to its full economic extent (Robinson et al. 2009; White et al. 2003). This study follows suit, reformulating all financial statements in order to bring onto the university balance sheet all unrecognised actuarial gains and losses and unrecognised past service costs.

Most of the universities hold financial investments, typically comprising money market instruments, bonds and equities. The effective analysis of investment performance requires the calculation of total holding period returns (Stewart, Piros \& Heisler 2011), calculated as the rand amount earned over a year divided by the rand amount invested at the start of the year. The numerator of this equation includes realised and unrealised gains and losses from price increases and decreases, as well as income distributions in the form of dividends and interest.

The accounting standards produce disclosures of investment returns that are almost completely at odds with the needs of professional investment practice, scattering the information on dividends, interest and capital gains and losses throughout the financial statements. In some cases, the investment return numbers are allocated to four, five, or even six different places in two different primary financial statements. For the purposes of this analytical framework, these numbers are recombined in order to establish a single usable measure of each institution's total annual return on financial investments.

The accounting rules require the division of the income statement into two parts. One of these displays the components of institutional revenue and expense, and the other contains various accounting numbers asserted by the standard-setter as being appropriate for exclusion from the main part of the income statement. Items in the latter category are referred to as other comprehensive income. In the context of this study, the relevant transactions for the South African universities include fair value changes to financial assets, revaluation adjustments to physical assets, and gains and losses relating to defined benefit plans. Rees and Shane (2012) draw attention to the absence from the 
standards of a coherent definition of other comprehensive income, suggesting that the rules for allocations of income and expenses to this category appear to be entirely arbitrary.

As a result, financial analysts have long been sceptical of the standard-setters' assertions of the decision-usefulness of such a structure. Penman (2013:263), for example, describes as 'appropriately pejorative' the 'clean' and 'dirty' surplus terms commonly used to describe the two bottom lines in the divided income statement. Therefore, in this study, all items of other comprehensive income are reassigned to the relevant revenue and expense lines of the income statement in order to restore it to a unified state.

The reporting regulations require that the South African universities maintain a 'separation between Recurrent and Non-Recurrent Income and Expenditure [which] must be strictly observed' (South Africa 2007:9). Given the regulatory prominence accorded to this separation (and even the attention paid to capitalising the words in question), it is curious that no definitions are stated, nor is guidance provided on the bases in terms of which accounting items are to be allocated between the recurring and non-recurring categories. A substantial number of university income statements during the review period simply ignore the distinction. Among those universities that do classify income and expense items on the basis of their nature as recurrent or non-recurrent, little consistency prevails, with clearly negative consequences to comparability. In addition, managerial decision-making on the likelihood of recurrence of a particular income or expense item is, demonstrably, arbitrary. However, neither lack of definition nor erratic compliance is of consequence to the study, because there is no support in modern practitioner or academic non-profit literature for the presumption that such a categorisation provides decision-useful information. Therefore, all recurring and non-recurring lines of the income statement are combined on a like-for-like basis in order to create a reunified document.

Prior year accounting restatements are made when an accounting policy is changed, or a material prior year error is detected in the current year. In either situation, the current year's financial report is published alongside reference (comparative) numbers from the prior year that differ from those originally published. According to the standard-setter, this requirement enhances the relevance and reliability of financial statements, as well as their comparability over time. This is a questionable assertion, for the following reason (the explanation is illustrated with an example based on actual events and amounts derived from this study, without naming the South African university involved).

Consider a university that makes an error, undetected at the time, in its 2015 financial statements, involving expenses of R347 million incorrectly recognised as PPE assets. The 2015 (audited) report therefore overstates institutional surplus, equity and assets by R347 million. These are the numbers used at the time by regulators and others in making subsidy funding and other economic decisions. In 2016, the error is discovered and reported. The accounting rules require that the correction be made against the previously published 2015 numbers; the only number from 2016 that is adjusted is the opening equity balance. This has the dramatic consequence that the accounting numbers affected by the error effectively disappear as reference points in the decision-making record. This happens because, firstly, the missing R347 million expense does not appear in the 2015 income statement at the time it was being used by decision-makers and, secondly, the amount remains unreported as an expense in the 2016 income statement. A further problem is that retrospective restatement of the current year's opening equity balance immediately breaks the logic of the intertemporal links in the financial statements, thereby obfuscating the effective longitudinal analysis of trends in the accounting numbers. In order to mitigate these negative effects, this study responds by reallocating the amount of prior year restatements to the relevant revenue and expense items in the current year.

Decades of academic research on the distortive effects of lease accounting rules (Imhoff, Lipe \& Wright 1991; Lipe 2001) were eventually followed by a reaction from the accounting standard-setter, which from 2019 requires the recognition of all lease assets and liabilities on the balance sheet. However, for the entire time frame of this study all operating lease obligations remain off balance sheet. The amounts involved are sometimes very large, in both absolute and relative terms. In 2012, for example, one of the smaller universities reported R872 million in (off balance sheet) future operating lease commitments; the total institutional capitalisation of this university was, in comparison, R898 million at the same date. Both academic and practitioner literature recommend the constructive capitalisation of operating leases, which results in the creation of a rightof-use asset and a corresponding liability, measured as the present value of future non-cancellable lease payments.

This study follows suit, applying South African prime overdraft rates to discount the operating lease payments disclosed in the notes to the universities' financial statements. Table 5 provides a summary of the accounting problems and the mechanisms applied in response.

All ratios for each institution, for each financial year, were then calculated from the standardised accounting numbers. Using Stata software, a total of 10 separate principal component analyses (PCA, one for each year; the technique is unsuitable for time-series or panel data) were then applied, taking into consideration the implications of the small number of cases in this study ( $N=23$ universities). Mundfrom, Shaw and Ke (2005) and Preacher and MacCallum (2002), among others, discuss minimum sample sizes for PCA. All present forceful critiques of the prescriptions and heuristics that are common in the standard textbooks. De Winter, Dodou and Wieringa (2009:147) show that, under the conditions applicable to this study, 'data are well conditioned ... [and] can yield 
TABLE 5: Summarised accounting transformations.

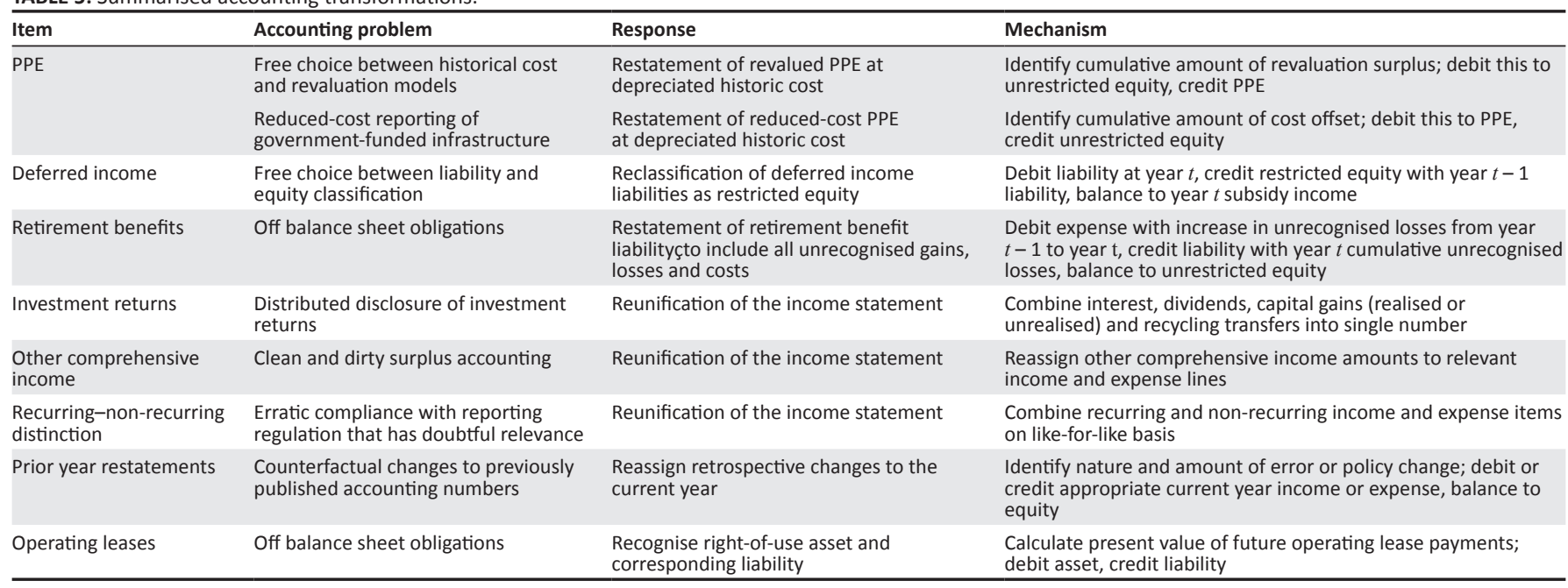

PPE, property, plant and equipment.

reliable results for $N$ well below 50.' Jung and Lee (2011) demonstrate the validity of PCA for $N$ as low as 15 .

For each of the 10 years of the review period, a correlation matrix was generated for the applicable variables.

The suitability of the matrix for PCA was evaluated using partial correlations and the Kaiser-Meyer-Olkin (KMO) (Kaiser 1970) measure of sampling adequacy. Hair et al. (2010) suggest that 0.50 be used as a KMO benchmark. In this small- $N$ situation, the minimum acceptable level for $\mathrm{KMO}$, for both individual variables and the overall matrix, was set substantially higher, at 0.70 . In an iterative process, the single variable with the lowest KMO less than 0.70 was deleted, and the correlation matrix was recalculated, until a correlation matrix was generated that passed the minimum KMO benchmark, as well as the Bartlett (1950) test of sphericity.

Each year's results were then inspected for compliance with the following benchmarks. Although Hair et al. (2010) recommend a minimum loading (i.e. correlation of each variable with each component) of 0.70, De Winter et al. (2009) suggest that a higher level is appropriate in a small- $N$ context (although they do not quantify this). In response, the minimum acceptable loading was set at 0.80 . For communalities (i.e. the sum of the squared loadings, across all components, for each variable), the Hair et al. recommended minimum is 0.50 . In this situation, the small- $N$ guidelines of Preacher and MacCallum (2002) were instead applied, and the communality benchmark was set at 0.70 . Variables not meeting the loading and communality criteria were eliminated, one by one (lowest first), until the principal component solution was in compliance with both benchmarks.

Kaiser (1960) establishes a minimum acceptable value for component eigenvalues (i.e. the column totals of squared correlations) at 1.0. The Cattell (1966) Scree Test is commonly used in confirmation of the eigenvalue criterion. However, these tests are vulnerable to challenges of arbitrariness and subjectivity, and therefore this study applied Horn's (1965) parallel analysis to identify the number of components to retain in each year. As reported below, this method resulted in the retention of one component throughout the research's time frame, and therefore neither orthogonal nor oblique rotations were applied.

\section{Results and discussion}

The results of these procedures identify, for each year from 2007 to 2016, a single component that explains $80 \%$ or more of the total variance in the universities' financial characteristics. In each year, between 7 and 10 ratios from the original set of 24 display the required minimum loading benchmark of 0.80 . Furthermore, all ratios consistently return positive correlations with the retained component, which is therefore interpreted as a single composite indicator of South African university financial health. Table 6 summarises these findings.

The two KPMG (2010) financial viability ratios, which measure the relationship between expendable assets and liabilities or debt (XATL and XATD), appear in all 10 years of the results. This suggests support, within this study's frame of reference, for the postulated long-term financial capacity dimension. A further two indicators, XACX (expendable assets as a ratio of cash expenses) and XAMX (with employee expenses as a denominator), are associated with the principal component in 9 out of 10 years. These findings are consistent with the Bowman (2011) short-term financial capacity interpretation, as well as those of at least three academic studies (Bennett, Iossa \& Lengrezi 2010; Bowman, Tuckman \& Young 2012; Fisman \& Hubbard 2005) and two practitioner monographs (Tschampion et al. 2012; Weisbrod et al. 2008).

The persistence of the four expendable asset ratios corroborates the proposition that liquid and unrestricted resources provide defensive financial capacity to the institution. When multiplied by 365 , for example, the expense-focused ratios measure the number of days that 
TABLE 6: Results of principal component analyses, 2007-2016.

\begin{tabular}{|c|c|c|c|c|c|c|c|c|c|c|}
\hline Variable & 2007 & 2008 & 2009 & 2010 & 2011 & 2012 & 2013 & 2014 & 2015 & 2016 \\
\hline UETA & - & - & - & - & - & 0.861 & 0.857 & 0.847 & & 0.856 \\
\hline XATL & 0.864 & 0.907 & 0.930 & 0.914 & 0.886 & 0.916 & 0.932 & 0.926 & 0.901 & 0.953 \\
\hline XATD & 0.872 & 0.905 & 0.914 & 0.897 & 0.916 & 0.877 & 0.881 & 0.952 & 0.931 & 0.961 \\
\hline XACX & - & 0.928 & 0.957 & 0.961 & 0.949 & 0.972 & 0.968 & 0.970 & 0.974 & 0.979 \\
\hline XAMX & 0.908 & - & 0.963 & 0.973 & 0.965 & 0.981 & 0.977 & 0.980 & 0.983 & 0.973 \\
\hline TICX & 0.877 & 0.981 & 0.951 & 0.918 & 0.903 & 0.895 & 0.923 & - & - & - \\
\hline TITX & 0.900 & 0.978 & 0.956 & - & 0.914 & - & - & 0.920 & 0.933 & 0.874 \\
\hline TIMX & 0.963 & 0.941 & - & 0.895 & 0.917 & & 0.846 & 0.867 & 0.922 & \\
\hline XATX & - & - & - & 0.963 & 0.949 & 0.973 & 0.961 & 0.975 & 0.974 & 0.980 \\
\hline TETR & 0.862 & 0.883 & - & - & - & - & - & - & - & - \\
\hline UEUR & - & - & - & - & - & - & 0.889 & 0.922 & 0.923 & 0.915 \\
\hline IRTR & 0.914 & - & 0.944 & 0.949 & 0.941 & 0.914 & 0.882 & 0.945 & 0.857 & - \\
\hline Explained variance $(\%)$ & 80.2 & 86.9 & 89.4 & 87.3 & 85.9 & 85.5 & 83.3 & 86.7 & 87.2 & 87.9 \\
\hline KMO & 0.865 & 0.881 & 0.842 & 0.833 & 0.795 & 0.865 & 0.844 & 0.850 & 0.827 & 0.855 \\
\hline Bartlett $d f$ & 28 & 21 & 21 & 28 & 36 & 28 & 45 & 45 & 36 & 28 \\
\hline Bartlett $p$-value & 0.000 & 0.000 & 0.000 & 0.000 & 0.000 & 0.000 & 0.000 & 0.000 & 0.000 & 0.000 \\
\hline
\end{tabular}

Note: Component retention determined using Horn's (1965) procedure. For clarity of presentation, loadings below 0.80 are not shown. Full ratio specifications are provided in the main text.

T, total; A, assets; L, liabilities; E, equity; D, debt; U, unrestricted; R, revenue; X, expenses; I, investments; M, employees; C, cash; $\chi^{2}$, chi squared; $d f$, degrees of freedom; UETA, unrestricted equity divided by total assets; XATL, expendable assets divided by total liabilities; XATD, total debt; XACX, cash expenses; XAMX, employee expenses (staff costs); TICX, total cash and financial assets divided by total assets; XATL, expendable assets divided by total liabilities; XATD, total debt; XACX, cash expenses; XAMX, employee expenses (staff costs); TICX, total cash and financial assets
divided by cash expenses; TITX, total expenses; TIMX, employee expenses (staff costs); XATX, total expenses; TETR, total equity divided by total revenue; UEUR, unrestricted equity divided by divided by cash expenses; TITX, total expenses; TIMX, employee expenses (staff costs); XATX, total expen
unrestricted revenue; IRTR, investment-source revenue divided by total revenue; KMO, Kaiser-Meyer-Olkin.

discretionary assets could support the relevant expense category. This analysis is reinforced by the presence of the total investment ratios in 7 of the 10 results: TICX (measuring the sufficiency of total cash and financial assets in relation to annual cash expenses), TITX (total expenses), and TIMX (employee expenses, also known as staff costs). Therefore, comprehensive measures of the institutional pool of cash and financial assets are similarly indicative of financial condition, when scaled on expenses that are broadly defined to include both restricted and unrestricted categories.

Three equity-related ratios are present in the results. The original Tuckman and Chang (1991) measure of equity adequacy, total equity divided by total revenue (TETR), appears in only two years. However, this study's variables include an alternative interpretation of this ratio based on unrestricted equity, and UEUR (with unrestricted revenue as the denominator) is found to be rather more persistent, with four occurrences.

This indicates some support for the relevance of unrestricted equity as a component of university financial resilience. Unrestricted equity as a ratio of total assets (UETA), this study's variation of the Bowman (2011) long-term capacity indicator, also appears in four years, and is similarly indicative of a direct relationship between financial condition and the proportion of total institutional assets that have been funded through capital sources that are neither debt nor restricted by donors. This interpretation aligns with the analyses of Calabrese (2011, 2013), Denison, Fowles and Moody (2014), and Jegers and Verschueren (2006).

The final ratio that emerges from the analysis is the proportion of investment-source revenue to total revenue (IRTR). This is present in eight years of the analysis, and is consistent with the Heutel and Zeckhauser (2014) expectation that a productive pool of financial investments contributes positively to the financial condition of a university.

The findings are as interesting for absent dimensions and ratios as they are for those that make an appearance. Firstly, none of the surplus-related ratios appears in the results, and therefore no evidence is found for the financial sustainability dimension, whether in long-term or short-term frames. The surplus indicators are all based on a predicate of financial capital preservation, achieved by keeping expenses lower than income, with the resultant surplus making a contribution to increasing equity over time. This seems secure as a theoretical construct, and the findings are therefore unexpected. However, further investigation suggests that this result is attributable to the small relative size and high volatility of annual surplus, rather than theoretical inconsistency. KPMG (2010) provides implicit support for this interpretation, allocating a combined weight of $30 \%$ to the two surplus ratios in their composite financial health index, in contrast with the $35 \%$ weight for each of the two expendable asset indicators. Similarly, Bowman et al. (2012), Calabrese (2013), and Ryan and Irvine (2012) argue that it is accumulated surplus (in other words, equity) that is a central source of financial sustainability. The absence of the surplus ratios from this study's results may therefore be attributable to an interpretation in which a single year deficit has little incremental consequence on financial condition. A university with a substantial equity balance has the financial capacity to cope with the situation, and one that is undercapitalised has already been identified by the indicator set as being in poor financial health.

Secondly, the revenue diversity indicator is absent from all 10 analyses. This outcome is less surprising, in light of challenges in the literature to the Tuckman and Chang (1991) proposition that financial stability is achievable through 
brute minimisation of an index originally designed for the economic analysis of market concentration. Kingma (1993) appears to be the first to apply portfolio theory to argue that an optimal mix of institutional revenue sources is achievable through a consideration of their variances and covariances, rather than by means of naïve diversification. The Hung and Hager (2019) meta-analysis of 40 subsequent investigations reports generally weak, non-existent, or negative relationships between revenue diversity and financial health. The current study is offered in modest support of these findings.

Finally, it is interesting to observe that differences in infrastructure intensity (which, for example, could be lower for universities focused on humanities rather than science and medicine) also appear to have no immediate relevance to the consideration of financial health. However, this outcome is attributable to the inherent nature of property and equipment as being illiquid and therefore unavailable for financial purposes (even though such assets are central to the university's mission). In addition, overinvestment in infrastructure (variously attributable to inter-university competitive pressures, managerial hubris, or corruption, among other factors) directly displaces the university's holdings of liquid financial assets, thereby contributing incremental financial pressures. Indicators representative of this dimension of financial health are prominent components of this study's results.

Attention is now turned to a consideration of the plausibility of the university financial health interpretation that has emerged from this research. For each institution in each year of the analysis, factor scores (calculated using the regression method) are extracted from the PCA results in order to determine a single composite measure of financial health. The 10-year mean, minimum, and maximum financial health scores and ranks are reported by institution in Table 7 .

For the 10-year period of this analysis, the maximum (best) composite financial health score is 6.19 and the minimum is -4.67 . The factor scoring method uses normalised versions of all variables, and so the 10-year mean score is, as expected, exactly 0.00 . Four institutions are ranked in first place on the basis of the financial health composite at least once during the review period, and three are placed 23rd at least once.

TABLE 7: Selected financial data by institution, 2007-2016.

\begin{tabular}{|c|c|c|c|c|c|c|c|c|c|c|c|c|}
\hline \multirow[t]{3}{*}{ University } & \multirow{2}{*}{\multicolumn{2}{|c|}{ Mean }} & \multicolumn{4}{|c|}{ Financial health } & \multicolumn{3}{|c|}{ Unrestricted surplus $\dagger$} & \multicolumn{3}{|c|}{ Savings $\dagger \dagger$} \\
\hline & & & \multicolumn{2}{|c|}{ Minimum } & \multicolumn{2}{|c|}{ Maximum } & \multicolumn{2}{|c|}{ Mean } & \multirow[t]{2}{*}{$\mathrm{CV}_{\ddagger}$} & \multicolumn{2}{|c|}{ Mean } & \multirow[t]{2}{*}{ CV } \\
\hline & Score $\S$ & Rank & Score & Rank & Score & Rank & R million & $\%$ & & R million & $\%$ & \\
\hline CPUT & -0.05 & 10.4 & -0.96 & 15 & 1.06 & 7 & 39.6 & 2.3 & 1.3 & -12.2 & -1.2 & 10.2 \\
\hline CUT & -1.80 & 15.6 & -3.70 & 21 & 0.61 & 8 & 20.6 & 4.9 & 2.9 & -8.9 & -6.3 & 8.8 \\
\hline DUT & -0.38 & 11.8 & -1.62 & 17 & 0.72 & 8 & 128.5 & 13.7 & 0.6 & 118.7 & 12.8 & 0.7 \\
\hline MUT & -2.82 & 19.8 & -3.48 & 21 & -2.12 & 18 & -8.3 & -6.3 & 0.9 & 22.0 & 11.0 & 1.6 \\
\hline NWU & -1.11 & 14.6 & -1.64 & 17 & -0.21 & 13 & 147.6 & 10.9 & 1.3 & 82.7 & 7.3 & 0.9 \\
\hline RU & -0.23 & 11.3 & -1.61 & 15 & 0.95 & 8 & 64.2 & 7.0 & 2.3 & 48.5 & 7.6 & 1.4 \\
\hline SU & 4.65 & 2.0 & 3.73 & 3 & 5.39 & 1 & 473.0 & 10.8 & 0.7 & 178.2 & 3.7 & 0.5 \\
\hline TUT & -1.69 & 16.4 & -2.99 & 21 & -0.79 & 12 & 113.3 & 15.6 & 0.8 & 69.1 & 9.7 & 3.4 \\
\hline UCT & 2.29 & 5.8 & 1.67 & 7 & 2.77 & 5 & 372.0 & 9.8 & 0.5 & 234.9 & 5.8 & 0.7 \\
\hline UFH & -3.76 & 22.5 & -4.32 & 23 & -3.07 & 22 & 13.5 & -45.8 & 4.9 & 28.4 & 8.1 & 2.5 \\
\hline UJ & 2.47 & 5.3 & 1.05 & 6 & 3.92 & 4 & 299.6 & 7.9 & 0.9 & 45.3 & 1.8 & 2.5 \\
\hline UKZN & -2.15 & 18.2 & -3.17 & 22 & -1.19 & 15 & 42.7 & -5.0 & 6.1 & 102.6 & 5.3 & 1.9 \\
\hline UL & -1.37 & 15.7 & -3.31 & 23 & 0.54 & 10 & 109.7 & -7.9 & 1.7 & 143.9 & 24.9 & 0.5 \\
\hline UNISA & 3.41 & 3.7 & 0.96 & 7 & 4.86 & 1 & 443.5 & 8.0 & 1.1 & -17.6 & 0.5 & 19.8 \\
\hline UV & -1.68 & 15.6 & -3.63 & 22 & 0.03 & 8 & 20.4 & 3.5 & 5.5 & 37.4 & 9.0 & 2.1 \\
\hline UWC & -0.79 & 13.1 & -1.61 & 17 & -0.28 & 10 & 109.1 & 10.2 & 0.9 & 143.5 & 14.4 & 0.9 \\
\hline UZ & -0.22 & 12.5 & -2.87 & 21 & 2.39 & 4 & 76.7 & 7.2 & 1.8 & 107.0 & 18.1 & 1.0 \\
\hline VUT & 1.13 & 8.1 & -0.71 & 12 & 2.90 & 5 & 81.1 & 10.3 & 1.1 & 71.1 & 13.0 & 1.7 \\
\hline Wits & -2.04 & 17.9 & -2.43 & 19 & -1.60 & 16 & 193.0 & 13.4 & 0.6 & 188.8 & 8.1 & 0.9 \\
\hline WSU & -3.53 & 21.7 & -4.67 & 23 & -1.83 & 18 & -33.6 & -70.7 & 2.8 & 35.2 & -16.6 & 6.5 \\
\hline All & 0.00 & 12.0 & -4.67 & - & 6.19 & - & 3971 & 9.8 & 0.6 & 2295 & 6.2 & 0.3 \\
\hline
\end{tabular}

Note: positive: net cash savings; negative, net drawdown of financial asset holdings.

$\dagger$, mean annual unrestricted surplus in million rand (percentage of unrestricted equity); $\$$, coefficient of variation (the higher this ratio, the more volatile the institution's annual surplus, or savings transfer: lower is better); $\S$, composite factor score calculated using the regression method (positive association with financial health: higher is better); $\uparrow$, mean, minimum, and maximum annual financial health rank for each university; $\dagger \dagger$, mean annual net cash flows linked to investments and cash in million rand (percentage of total financial assets).

CPUT, Cape Peninsula University of Technology; CUT Central University of Technology; DUT, Durban University of Technology; MUT, Mangosuthu University of Technology; NMU, Nelson Mandela University; NWU, North-West University; RU, Rhodes University; SU, Stellenbosch University; TUT, Tshwane University of Technology; UCT, University of Cape Town; UFH, University of Fort Hare; UFS, University of the Free State; UJ, University of Johannesburg. UKZN, University of KwaZulu-Natal; UL, University of Limpopo: UNISA, University of South Africa; UP, University of Fort Hare; UFS, University of the Free State; UJ, University of Johannesburg; UKZN, University of KwaZulu-Natal; UL, University of Limpopo; UNISA, University of South Africa; UP, University of Pretoria; UV, University of Venda; Wits, University of the Witwatersrand; UWC, University of the Western Cape; UZ, University of Zululand; VUT, Vaal University of Technology; WSU, Walter Sisulu University. CPUT, Cape Peninsula University of Technology; CUT Central University of Technology; DUT, Durban University of Technology; MUT, Mangosuthu University of Technology; NMU, Nelson Mandela University; NWU, North-West University; RU, Rhodes University; SU, Stellenbosch University; TUT, Tshwane University of Technology; UCT, University of Cape Town; UFH, University of Fort Hare; UFS, University of the Free State; UJ, University of Johannesburg; UKZN, University of KwaZulu-Natal; UL, University of Limpopo; UNISA, University of South Africa; UP, University of Pretoria; UV, University of Venda; Wits, University of the Witwatersrand; UWC, University of the Western Cape; UZ, University of Zululand; VUT, Vaal University of Technology; WSU, Walter Sisulu University. 
Some universities display considerable 10-year stability in score and rank, with little variation between mean, minimum and maximum, while others are substantially more mobile.

Table 7 also reports 10-year means for each institution's unrestricted surplus and savings. Because neither quantity was included in the PCA phase, they provide an alternative context for evaluating the validity of the institutional financial health scores. Unrestricted surplus is presented here as a single long-term mean, in contrast with its inclusion as 10 separate one-year quantities in the original phase of the analysis. Savings is defined as net annual transfers of cash into (positive) or out of (negative) the institutional pool of cash and financial assets. Given the demonstrated significance of a university's year-end stock of liquid unrestricted assets, there is a reasonable expectation that the related annual flows would be similarly indicative of financial health.

Four universities (SU, UFS, UNISA, and UP) are placed in the highest quintile of mean financial health scores.

Their 10-year average annual unrestricted surpluses are large in both absolute amount (R300 million or more) and as a percentage of unrestricted equity (minimum 8.0\%). Furthermore, annual surplus for this group has low levels of relative annual volatility (maximum coefficient of variation: 1.0). Three institutions in this group have consistently high savings rates, with a minimum R178 million annual average net additions to financial assets. The single exception is UNISA, whose large net investment drawdowns in the last three years of the review were accompanied by a deterioration in both financial health score and rank.

Four universities (MUT, UFH, UKZN, and WSU) have mean financial health scores in the lowest quintile.

All have operated at an average annual deficit (in absolute terms, relative to equity, or both) over the 10-year review period. Although all four made net average annual cash additions to investments, the amounts involved are small. Furthermore, the individual savings transfers show substantial year-on-year inconsistency, with generally high variation coefficients.

In the central quintiles, the universities display a range of unrestricted surplus and savings metrics that generally associate in the expected manner with this study's overall financial health composites. For example, UJ is placed in the second-highest financial health quintile. Although it has surplus data which are comparable with universities in the highest group, its savings rates are noticeably lower and have higher annual volatility.

Similarly, CUT is in the second-lowest group, and is distinguished from institutions in the category below on the basis of having an average annual surplus (albeit small) rather than a deficit, while also reporting the same net average withdrawals from savings that are characteristic of the lowest-ranked universities.
It is neither the objective nor within the scope of this research to carry out a detailed financial review of the entire population of universities. However, there appears to be a coherent relationship between the composite financial health scores and two separate indicators which were excluded from the main analysis, on the basis of their absence from this study's three foundational models. In general, the financial health score is found to be positively associated with 10-year mean surplus and savings, and negatively associated with volatility in the same indices.

Individual nuances in this interpretation are not reported, but were separately investigated and found to be explainable in terms of longitudinal trends in institution-level financial data. In particular, these additional considerations included a comparison of 10-year comparative growth rates in income, expenses, assets, and equity. The example of UCT provides illuminating detail for this additional analysis. This institution is placed outside the top quintile in this article's results, despite displaying mean surplus and savings data that are comparable to the highest-ranked institutions. However, further examination reveals that this university's 10-year growth rate in total revenues (average annual rate: 11.3\%) compares unfavourably with both total expense growth $(12.1 \%)$, and the expansion rate in total assets $(12.9 \%)$. Neither situation is generally supportive of long-term financial sustainability. In particular, the revenue-expense growth mismatch, if continued long enough, will have the initial consequence of eliminating the university's annual surplus, followed by a persistent and growing series of deficits, with negative consequences on equity. Similarly, the revenue-asset growth mismatch is an adverse financial signal of decreasing self-funding capacity for this institution.

Other characteristics of the South African universities are now considered, in order to determine whether these provide incremental support for this study's evaluation of institutional financial health. Table 8 reports each university's administrative classification, historical context, circumstances of merger, geographic separation, and institution size (in both financial and enrolment terms). The last column of Table 8 places each institution in a financial health quintile on the basis of this study's 2007-2016 average composite factor scores. Table 9 provides average financial health scores for each characteristic, classified into the relevant categories.

A number of interesting associations are evident, although some characteristics lack any clear relationship with financial condition. For example, financial health is not coherently distributed among South African public universities on the basis of the classification framework applied by the Department of Higher Education and Training. Table 8 shows that institutions in each of the three regulatory clusters (traditional universities, universities of technology, and comprehensive universities) are scattered across the financial condition continuum, with one notable result being that the group of three institutions evaluated as having the poorest financial condition includes a member of each of 
the three clusters. Although Table 9 indicates that universities of technology have a substantially lower average financial health score, this outcome appears to be explainable by historic context rather than administrative classification, as discussed below. Given generally high levels of heterogeneity in mission and educational focus among institutions within each cluster, the absence of a discernible relationship between administrative group and financial health is arguably an unsurprising result.

In terms of historical context, there were 36 public higher education institutions in South Africa in 2001. Four years later, a series of mergers, campus carve-outs, and dissolutions had reduced this number to 23 . The necessity for this process was attributed by the then Minister of Education to a system still burdened by apartheid, which remained fragmented on race lines. Although the merger policy framework also specified the efficient use of limited resources, no substantive details were provided on the mechanisms by means of which the reduced set of public universities was also to achieve financial sustainability.
Mergers are famously risky endeavours, in both commercial and non-profit frames of reference. Of particular interest for the current study is the Stahl and Voigt (2006) cultural difference hypothesis, in terms of which incongruent histories have lasting adverse consequences on the effective integration of the merged entity. In South Africa, such cultural incongruences arose in two main ways (which sometimes intersected): the merger of technikons and traditional universities to form comprehensive universities, and the merger of historically black and historically white institutions. A number of South African studies (Arnolds \& Boshoff 2004; Hay \& Fourie 2002; Wyngaard \& Kapp 2004) concentrate on adverse social effects, variously describing depression, fear, loss of self-esteem and reduced organisational commitment in post-merger universities. Mabokela and Wei (2007) and Sehoole (2005) argue that inadequacies in institutional leadership may explain the lingering negative effects of complex mergers of South African universities. Bunting (2006) describes black higher education institutions in pre-1994 South Africa as being characterised by authoritarian

TABLE 8: Selected characteristics of the universities: Institutional details.

\begin{tabular}{|c|c|c|c|c|c|c|}
\hline Variable & Cluster§ & Historical context & Campus separation $\dagger$ & Financial size & Enrolment size & Financial health quintile $+\dagger$ \\
\hline CPUT & Uot & Merger of HBT \& HWT & No & Medium & Medium & 2nd highest \\
\hline CUT & UoT & Merger of HWT \& $1 \mathrm{HBU}$ campus & Yes & Small & Small & 2nd lowest \\
\hline DUT & UoT & Merger of HBT \& HWT & No & Medium & Medium & Central \\
\hline MUT & UoT & HBT & No & Small & Small & Lowest \\
\hline NMU & Comp & Merger of HWU, HWT \& 1 HBU campus & No & Medium & Medium & 2nd highest \\
\hline NWU & Trad & Merger of HWU \& HBU & Yes & Medium & Large & Central \\
\hline SU & Trad & HWU & No & Large & Medium & Highest \\
\hline TUT & Uot & Merger of 2 HBTs \& 1 HWT & Yes & Medium & Large & 2nd lowest \\
\hline UCT & Trad & HWU & No & Large & Medium & 2nd highest \\
\hline UFH & Trad & Merger of HBU \& 1 HWU campus & Yes & Small & Small & Lowest \\
\hline UFS & Trad & Merger of HWU \& $1 \mathrm{HBU}$ campus & No & Medium & Medium & Highest \\
\hline UJ & Comp & Merger of HWU, HWT \& 2 HBU campuses & Yes & Large & Large & 2nd highest \\
\hline UKZN & Trad & Merger of HWU \& HBU & Yes & Large & Large & Lowest \\
\hline UNISA & Comp & Merger of HWU, HWT \& 1 HBU division & No & Large & Large & Highest \\
\hline UP & Trad & Merger of HWU \& $1 \mathrm{HBU}$ campus & Yes & Large & Large & Highest \\
\hline UV & Comp & $\mathrm{HBU}$ & No & Small & Small & 2nd lowest \\
\hline Wits & Trad & HWU & No & Large & Large & Central \\
\hline UWC & Trad & Merger of $\mathrm{HBU}$ and $1 \mathrm{HWU}$ school & No & Medium & Medium & Central \\
\hline UZ & Comp & $\mathrm{HBU}$ & No & Small & Small & 2nd highest \\
\hline VUT & UoT & Merger of HWT and $1 \mathrm{HBU}$ campus & Yes & Small & Small & 2nd lowest \\
\hline WSU & Comp & Merger of $\mathrm{HBU}$ and $2 \mathrm{HBTs}$ & Yes & Medium & Medium & Lowest \\
\hline
\end{tabular}

$\dagger$, Author's assessment of the significance of geographical separation of university campuses; $\$$, relative size determined on basis of 2016 total revenues. See Appendix 1 for further details; $\S$, administrative classification by Department of Higher Education and Training; $\uparrow$, relative size determined on basis of 2016 headcount student enrolments; $\dagger \dagger$, determined on the basis of this study's average 2007-2016 financial health score. See Table 7.

UoT, university of technology; Comp, comprehensive university; Trad, traditional university; HBT, historically black technikon (university); HBT(U), historically black technikon (university); HWT(U), historically white technikon (university); CPUT, Cape Peninsula University of Technology; CUT Central University of Technology; DUT, Durban University of Technology; MUT, Mangosuthu University of Technology; NMU, Nelson Mandela University; NWU, North-West University; RU, Rhodes University; SU, Stellenbosch University; TUT, Tshwane University of Technology; UCT, University of Cape Town; UFH, University of Fort Hare; UFS, University of the Free State; UJ, University of Johannesburg; UKZN, University of KwaZulu-Natal; UL, University of Limpopo; UNISA, University of South Africa; UP, University of Pretoria; UV, University of Venda; Wits, University of the Witwatersrand; UWC, University of the Western Cape; UZ, University of Zululand; VUT, Vaal University of Technology; WSU, Walter Sisulu University.

TABLE 9: Average financial health score by characteristic.

\begin{tabular}{|c|c|c|c|c|c|c|c|c|c|c|c|c|c|}
\hline \multicolumn{3}{|c|}{ Cluster } & \multicolumn{2}{|c|}{ Merger impact $\dagger \dagger$} & \multicolumn{2}{|c|}{ Precursor HBI } & \multicolumn{2}{|c|}{ Campus separation } & \multicolumn{3}{|c|}{ Financial size } & \multicolumn{2}{|c|}{ Size mismatch } \\
\hline Trad & Comp & UoT & Low & High & Not & Yes $\dagger$ & No & Yes & $L$ & $M$ & $S$ & Pos.§ & Neg.ף \\
\hline 0.60 & 0.37 & -1.46 & 0.65 & -0.71 & 0.94 & -0.72 & 0.47 & -0.72 & 2.07 & -1.30 & -0.39 & 0.62 & -0.57 \\
\hline
\end{tabular}

$\dagger$, unmerged historically black institution or merged university includes an institution-level HBI precursor component; $\$$, all other universities, including those that incorporated only the local Vista University campus; $\$$, financial size is greater than or equal to enrolment size; f, financial size is less than enrolment size; $\dagger$, Low merger impact: unmerged institutions, those that incorporated only the local campus or school of another university, and those affected only by a campus or school carve-out. High merger impact: all institution-level mergers, plus UFH.

HBI, historically black institution; Trad, traditional university; Comp, comprehensive university; UoT, university of technology; L, large; M, medium; S, small; Pos., positive; Neg., negative. 
governance structures, a lack of administrative capacity, and the absence of financial autonomy.

It therefore seems reasonable to expect that, in 2016, these adverse historical conditions would continue to have social and financial consequences for the affected South African universities. In seeking support for its construct of financial health, this article fortuitously offers some evidence in support of the matter. As reported in Table 9, the low-impact merger group (comprising universities unaffected by merger, and those that incorporated only a local campus or school of another university) has a dramatically higher average financial health score than the group of universities formed from major (institution-level) mergers. A similar result is found when the universities are categorised on the basis of formation from a precursor historically black institution. The average financial health score for this group of institutions is materially lower than for all other South African universities. Finally, merged universities with geographically distant campus locations face incremental administrative challenges, as well as higher cost structures, which are likely to have detrimental effects on financial health. Table 9 provides support for this analysis, with the financial health score showing a clear association, in the expected direction, with campus separation.

Institutional size in 2016 is reported in Table 8 in financial terms (measured by total annual revenues) as well as on the basis of student enrolments. Calabrese (2013), Lecy and Searing (2015), and Mosley et al. (2012) report a positive relationship between non-profit organisational size and financial strength. In contrast, this study finds only equivocal support for this proposition. There is no monotonicity in the relationship between the size of a South African university's annual revenues and its financial health score, although the largest universities (measured on a revenue basis) do have the highest average levels of financial health. A plausible interpretation is that the blurring of the expected relationship in a South African context is attributable to the persistent consequences of historical circumstance. In addition, when the relative sizes of total revenues and student enrolments are considered in combination, substantially higher average levels of financial health are found for those South African universities whose financial size exceeds (or at least equals) student enrolment size. Thus, this study's financial health score is consistent with an interpretation of financial vulnerability arising from a situation in which a university with relatively low revenues in comparison with its peers is burdened with a relatively high student enrolment level.

\section{Conclusion}

The South African universities that are the subject of analysis in this article exist within an economic partition substantially different from that which applies to corporations. This calls into question any presumption that a financial analysis approach designed for the latter context will, self-evidently, be suitable for the former.
Although the matter has attracted considerable international academic attention, no definitive solution has yet emerged in response to the problems of identifying the dimensionality of non-profit financial condition, or the applicable ratios. Furthermore, South African universities have not been subjected to comparably comprehensive academic studies of financial condition - although this national context is, in contrast, notable for its significant number of competing practitioner and regulator models.

However, this study represents neither a mere replication of established methods in a lesser examined frame of reference, nor an attempt to establish a normative framework with asserted suitability for the financial management of South African universities. Instead, the article offers a contribution to the literature in the following ways. Firstly, despite the well-known existence of serious errors in the data sources, non-profit research has, to date, provided no substantive response to the problem. In this study, the data were directly obtained from primary sources and subjected to rigorous cross-checking, and all anomalies were investigated and resolved, rather than being eliminated as so-called outliers.

A second unaddressed concern in accepting the results of prior research relates to deficiencies of representational validity and comparability in the accounting numbers which populate the commonly used non-profit databases. Actions in suitable mitigation are taken in none of the existing large database studies. In contrast, this article makes the necessary adjustments to the data in order to respond to inadequacies of comparability, as well as to increase the level of correspondence between each problematic accounting number and the related real-world economic phenomenon. The international literature has not explored the question of whether the lack of consensus on the defining characteristics of non-profit financial condition may (at least partially) be attributable to data errors and accounting problems, and this study therefore contributes to filling a gap in the research record. Finally, the country of focus in this article is a place in which both history and current realities have brought about a society that remains 'fundamentally flawed by inequities, imbalances and distortions' (National Commission on Higher Education 1996:1). An important contribution of this study therefore lies in its acceptance of the challenge to evaluate its postulated construct of university financial health within a unique national setting that is marked by heterogeneity of historical circumstance, administrative classification, circumstances of merger, geographic separation, and student enrolments.

The method and findings of this research may be summarised as follows. Three prominent but competing models of nonprofit financial condition were selected from the literature on the basis of prominence of citation, practitioner relevance, and recent innovation. Each ratio from these models was given an equal opportunity to present itself as demonstrably 
representative of university financial health. This approach allowed for one of three different outcomes for the research: that one of the models would be found to dominate the other two, because its full ratio set crowded out all alternatives, or that a subset of ratios from different models would be associated with financial condition, or that all ratios would be found to be irrelevant. In this manner, the three models were considered both as unified constructs, as well as in terms of their individual indicators.

None of the models is found to provide a unified and coherent representation of South African public university financial health. In addition, none of the Tuckman and Chang (1991) indicators emerges in its original formulation as having convincing relevance in this frame of reference. However, evidence is presented in support of the existence of the KPMG (2010) financial viability dimension, as measured by two ratios which scale the university's expendable assets against its indebtedness to financial institutions, as well as against its liabilities, more broadly defined. Two ratios from Bowman (2011) are also identified as relevant to the consideration of South African university financial condition, reinforcing an interpretation of financial capacity as being associated with indicators that measure the adequacy of expendable assets in relation to expenses. These results corroborate the conjecture that liquid and unrestricted resources provide defensive financial capacity to the institution. The article also finds support for the relevance of capital structure as a component of university financial condition, with a number of indicators (including one that is reformulated from the Tuckman-Chang set) linked to unrestricted equity. These suggest an association between university financial condition and a balance sheet that is funded through accumulated surplus rather than borrowing, conditional donations, or restricted transfers.

This article represents, in the first instance, an academic endeavour, intended for placement within a body of literature on the characteristics of university financial health. Although it is also offered as a contribution to those for whom the wellbeing of South African public higher education is a matter of personal, institutional, or regulatory concern, the framework is notclaimed to be appropriate, without careful consideration, as a financial managerial or state policy instrument. However, it may well be the case that this study contributes some utility to informing the development of normative financial models for the universities. At the very least, it seems reasonable to suggest that the indicators might be helpful in telling the higher education analyst or university manager where to start looking for reasons that an institution's financial condition is in an unsatisfactory state. In this respect, one potentially useful mechanism might be the longitudinal and cross-sectional consideration of four ratios: expendable assets as a percentage of both assets and expenses, and unrestricted equity as a percentage of both capital and expenses. A decreasing trend in any of these indicators, or persistently unfavourable comparison with the national averages, is likely to be a red flag for institutional financial health that warrants managerial investigation and response.

The applicable 10-year review period for this research includes the international financial crisis which commenced in 2008. Although the interpretation of university financial condition maintains reasonable stability of construct during the global economic turmoil, more recent developments in South Africa will also have significant financial consequences for the universities. This article's findings predict that institutions with greater relative proportions of both expendable assets and unrestricted equity will prove to be more capable of withstanding the adverse financial effects of widespread student protests, a government-imposed fee freeze for 2016 (partially extended into 2017 and 2018), and service staff in sourcing (re-employment) demands.

However, this conjecture remains untested for the time being.

It is also appropriate to acknowledge the three new South African public universities that were constituted after 2014, and therefore excluded from the study. The decisionusefulness of this article's indicator set, within a context that is expanded to include institutions in their very early developmental phases, is not self-evidently secure. At this point, the matter remains a question for future research.

Other potentially fruitful lines of academic enquiry are available for future consideration. Notably, it will be interesting to extend this study's methodology to some of the other small-population frames of reference that are in widespread existence outside Europe and the United States. Cross-country and multinational investigations of university financial condition hold particular promise, given that this article finds substantial support for its financial condition indicators when these are considered in the context of national history and current circumstance. In addition, the possibility exists that a consideration of hybrid organisations (Battilana \& Dorado 2010; Glynn 2000; Heimer 1999) and new public management (Hood 1995; Manning 2001; Talib 2003) might usefully inform the determination of university financial health. Finally, Watkins (2000) and Tinkelman and Donabedian (2009) argue that the lack of consensus on non-profit financial condition is indicative of a need to turn to mission-focused (non-financial) data. However, the findings of this article suggest that such a conclusion may be ahead of its time, with at least equivalent promise being plausibly obtainable through an extension of non-profit financial condition research to a wider range of countries, as well as paying closer attention to the information quality of financial databases in common use in large-population studies.

\section{Acknowledgements}

The author acknowledges the helpful comments of two anonymous reviewers. 


\section{Competing interests}

The author declares that there are no financial or personal relationships that may have inappropriately influenced the writing of this article.

\section{Author's contributions}

The author declares that he is the sole author of this research article.

\section{Funding information}

The author received no financial or other support that facilitated conduct of the work described in the article or the writing of the article itself.

\section{Ethical consideration}

There are no ethical considerations or concerns regarding this research.

\section{Data availability statement}

Data sharing is not applicable to this article as no new data were created in this study.

\section{Disclaimer}

The views expressed in the submitted article are those of the author, and not an official position of any institution or funder.

\section{References}

Altman, E.I., 1968, 'Financial ratios, discriminant analysis and the prediction of corporate bankruptcy', Journal of Finance 23(4), 589-609. https://doi.org/ 10.1111/j.1540-6261.1968.tb00843.x

Arnolds, C.A. \& Boshoff, C., 2004, 'The management of the early stages of restructuring in a tertiary-education institution - An organisational commitment perspective South African Journal of Business Management 35(2), 1-13. https://doi.org/ 10.4102 /sajbm.v35i2.652

Bartlett, M.S., 1950, 'Tests of significance in factor analysis', British Journal of Statistical Psychology 3(2), 77-85. https://doi.org/10.1111/j.2044-8317.1950. tb00285.x

Battilana, J. \& Dorado, S., 2010, 'Building sustainable hybrid organizations: The case of commercial microfinance organizations', Academy of management Journal 53(6), 1419-1440. https://doi.org/10.5465/amj.2010.57318391

Bennett, J., lossa, E. \& Lengrezi, G., 2010, 'Commercial activity as insurance: The investment behaviour of non-profit organizations', Annals of Public and Cooperative Economics 81(3), 445-465. https://doi.org/10.1111/j.1467-8292. 2010.00417.x

Bowman, W., 2011, 'Financial capacity and sustainability of ordinary nonprofits', Nonprofit Management and Leadership 22(1), 37-51. https://doi.org/10.1002/ $\mathrm{nml} .20039$

Bowman, W., Tuckman, H.P. \& Young, D.R., 2012, 'Issues in nonprofit finance research: Surplus, endowment and endowment portfolios', Nonprofit and Voluntary Sector Quarterly 41(4), 560-579.

Bunting, I., 2006, 'Funding and students', in N. Cloete, P. Maassen, R. Fehnel, T. Moja, T. Gibbon \& H. Perold (eds.), Transformation in higher education: Global pressures and local realities, pp. 69-117, Springer, Dordrecht.

Calabrese, T.D., 2011, 'Testing competing capital structure theories of nonprofit organizations', Public Budgeting and Finance 31(3), 119-143. https://doi.org/ 10.1111/j.1540-5850.2011.00989.x

Calabrese, T.D., 2013, 'Running on empty: The operating reserves of US nonprofit organizations', Nonprofit Management and Leadership 23(3), 281-302. https://doi.org/10.1002/nml.21064

Cascino, S., Clatworthy, M., Osma, B.G., Gassen, J., Imam, S. \& Jeanjean, T., 2013, The use of information by capital providers: Academic literature review, ICAS, Edinburgh.

Cattell, R.B., 1966, 'The scree test for the number of factors', Multivariate Behavioral Research 1(2), 245-276. https://doi.org/10.1207/s15327906mbr0102_10

Chabotar, K.J., 1989, 'Financial ratio analysis comes to nonprofits', Journal of Higher Education 60(2), 188-208. https://doi.org/10.2307/1982176
Chang, C.F. \& Tuckman, H.P. 2010, 'Income diversification', in B.A. Seaman \& D.R. Young (eds.) Handbook of research on nonprofit economics and management, pp. 5-17, Edward Elgar, Cheltenham.

Chu, D.K.W., Zollinger, T.W., Kelly, A.S. \& Saywell, R.M., 1991, 'An empirical analysis of cash flow, working capital, and the stability of financial ratio groups in the hospital industry', Journal of Accounting and Public Policy 10(1), 39-58. hospital industry', Journal of Accounting and
https://doi.org/10.1016/0278-4254(91)90019-G

Christensen, H.B. \& Nikolaev, V.V., 2013, 'Does fair value accounting for non-financial assets pass the market test?', Review of Accounting Studies 18(3), 734-775. https://doi.org/10.1007/s11142-013-9232-0

Denison, D., Fowles, J. \& Moody, M.J., 2014, 'Borrowing for college: A comparison of long-term debt financing between public and private, nonprofit institutions of higher education', Public Budgeting and Finance 34(2), 84-104. https://doi.org/ 10.1111/pbaf.12034

Department of Higher Education and Training, 2018, Statistics on post-school education and training in South Africa: 2016, Department of Higher Education and Training, Pretoria.

De Villiers, A.P. \& Steyn, A.G.W., 2009, 'Effect of changes in state funding of higher education on higher education output in South Africa: 1986-2007', South African Journal of Higher Education 23(1), 43-68. https://doi.org/10.4314/sajhe. v23i1.44801

De Winter, J.C.F., Dodou, D. \& Wieringa, P.A., 2009, 'Exploratory factor analysis with small sample sizes', Multivariate Behavioral Research 44(2), 147-181. https://doi. org/10.1080/00273170902794206

Feltham, G.A. \& Ohlson, J.A., 1995, 'Valuation and clean surplus accounting for operating and financial activities', Contemporary Accounting Research 11(2), 689-731. https://doi.org/10.1111/j.1911-3846.1995.tb00462.x

Fisman, R. \& Hubbard, R.G., 2005, 'Precautionary savings and the governance of nonprofit organizations', Journal of Public Economics 89(11-12), 2231-2243. https://doi.org/10.1016/j.jpubeco.2004.10.005

Glynn, M.A., 2000, 'When cymbals become symbols: Conflict over organizational identity within a symphony orchestra', Organization Science 11(3), 285-298. https://doi.org/10.1287/orsc.11.3.285.12496

Greenlee, J.S. \& Trussel, J.M., 2000, 'Predicting the vulnerability of charitable organizations', Nonprofit Management and Leadership 11(2), 199-210. https:// doi.org/10.1002/nml.11205

Hager, M.A., 2001, 'Financial vulnerability among arts organizations: A test of the Tuckman-Chang measures', Nonprofit and Voluntary Sector Quarterly 30(2), 376-392. https://doi.org/10.1177/0899764001302010

Hair, J.F., Black, W.C., Babin, B.J. \& Anderson, R.E., 2010, Multivariate data analysis (7e), Pearson, Upper Saddle River, NJ.

Hansmann, H., 1980, 'The role of nonprofit enterprise', Yale Law Journal 89(5), 835-901. https://doi.org/10.2307/796089

Hay, D. \& Fourie, M., 2002, 'Preparing the way for mergers in South African higher and further education institutions: An investigation into staff perceptions', Higher Education 44(1), 115-131. https://doi.org/10.1023/A:1015569229047

Heimer, C.A., 1999, 'Competing institutions: Law, medicine, and family in neonata intensive care', Law and Society Review 33(1), 17-66. https://doi.org/10.2307/ 3115095

Heutel, G. \& Zeckhauser, R., 2014, 'The investment returns of nonprofit organizations, Part I: Tales from 990 forms', Nonprofit Management and Leadership 25(1), 41-57. https://doi.org/10.1002/nml.21100

Hirschman, A.O., 1964, 'The paternity of an index', American Economic Review 54(5), 761-762.

Hood, C., 1995, 'The new public management in the 1980s: Variations on a theme', Accounting Organizations and Society 20(2-3), 93-109. https://doi.org/10. Accounting, Organizations and

Horn, J.L., 1965, 'A rationale and test for the number of factors in factor analysis', Psychometrika 30(2), 179-185. https://doi.org/10.1007/BF02289447

Hung, C. \& Hager, M.A., 2019, 'The impact of revenue diversification on nonprofit financial health: A meta-analysis', Nonprofit and Voluntary Sector Quarterly 48(1), 5-27. https://doi.org/10.1177/0899764018807080

Imhoff, E.A., Lipe, R.C. \& Wright, D.W., 1991, 'Operating leases: Impact of constructive capitalization', Accounting Horizons 5(1), 51-63.

Jegers, M. \& Verschueren, I., 2006, 'On the capital structure of non-profit organisations: An empirical study for Californian organisations', Financial Accountability and Management 22(4), 309-329. https://doi.org/10.1111/j.1468-0408.2006.00428.x

Jung, S. \& Lee, S., 2011, 'Exploratory factor analysis for small samples', Behavior Research Methods 43(3), 701-709. https://doi.org/10.3758/s13428-011-0077-9

Kaiser, H.F., 1960, 'The application of electronic computers to factor analysis', Educational and Psychological Measurement 20(1), 141-151. https://doi.org/ $10.1177 / 001316446002000116$

Kaiser, H.F., 1970, 'A second generation little jiffy', Psychometrika 35(4), 401-415. https://doi.org/10.1007/BF02291817

Kingma, B.R., 1993, 'Portfolio theory and nonprofit financial stability', Nonprofit and Voluntary Sector Quarterly 22(2), 105-119. https://doi.org/10.1177/ 089976409302200202

KPMG, 2010, Strategic financial analysis for higher education: Identifying, measuring and reporting financial risks, 7th edn., KPMG, New York.

Lecy, J.D. \& Searing, E.A., 2015, 'Anatomy of the nonprofit starvation cycle: An analysis of falling overhead ratios in the nonprofit sector', Nonprofit and Voluntary Sector Quarterly 44(3), 539-563. https://doi.org/10.1177/0899764014527175 
Lipe, R.C., 2001, 'Lease accounting research and the G4+1 proposal', Accounting Horizons 15(3), 299-310. https://doi.org/10.2308/acch.2001.15.3.299

Mabokela, R.O. \& Wei, N., 2007, 'Lingering effects of the past on a university merger process in post-apartheid South Africa', International Education Journal 8(1) 160-171.

Manning, N., 2001, 'The legacy of the new public management in developing countries', International Review of Administrative Sciences 67(2), 297-312. https://doi.org/10.1177/0020852301672009

Mitchell, G.E., 2017, 'Fiscal leanness and fiscal responsiveness: Exploring the normative limits of strategic nonprofit financial management', Administration and Society 49(9), 1272-1296. https://doi.org/10.1177/0095399715581035

Mosley, J.E., Maronick, M.P. \& Katz, H., 2012, 'How organizational characteristics affect the adaptive tactics used by human service nonprofit managers confronting affect the adaptive tactics used by human service nonprofit managers confronting
financial uncertainty', Nonprofit Management and Leadership 22(3), 281-303. https://doi.org/10.1002/nml.20055

Mundfrom, D.J., Shaw, D.G. \& Ke, T.L., 2005, 'Minimum sample size recommendations for conducting factor analyses', International Journal of Testing 5(2), 159-168. https://doi.org/10.1207/s15327574ijt0502_4

National Commission on Higher Education, 1996, A framework for transformation, NCHE, Pretoria.

Newhouse, J.P., 1970, 'Toward a theory of nonprofit institutions: An economic mode of a hospital', American Economic Review 60(1), 64-74.

Ohlson, J.A., 1980, 'Financial ratios and the probabilistic prediction of bankruptcy', Journal of Accounting Research 18(1), 109-131. https://doi.org/10.2307/2490395

Ou, J.A. \& Penman, S.H., 1989, 'Financial statement analysis and the prediction of stock returns', Journal of Accounting and Economics 11(4), 295-329. https://doi.org/10.1016/0165-4101(89)90017-7

Parsons, L.M. \& Trussel, J.M., 2009, 'Fundamental analysis of not-for-profit financial statements: An examination of financial vulnerability measures', Research in Governmental and Nonprofit Accounting 12, 35-56.

Penman, S.H., 2013, Financial statement analysis and security valuation, 5th edn. McGraw-Hill, New York.

Preacher, K.J. \& MacCallum, R.C., 2002, 'Exploratory factor analysis in behavior genetics research: Factor recovery with small sample sizes', Behqvior Genetics genetics research: Factor recovery with small sample sizes',
32(2), 153-161. https://doi.org/10.1023/A:1015210025234

Prentice, C.R., 2016, 'Why so many measures of nonprofit financial performance? Analyzing and improving the use of financial measures in nonprofit research', Nonprofit and Voluntary Sector Quarterly 45(4), 715-740. https://doi.org/ 10.1177/0899764015595722

PricewaterhouseCoopers, 2014, Moving forward: Trends in annual reporting by South African public universities, PricewaterhouseCoopers, Johannesburg.

Rees, L.L. \& Shane, P.B., 2012, 'Academic research and standard-setting: The case of other comprehensive income', Accounting Horizons 26(4), 789-815. https://doi.org/10.2308/acch-50237

Ritchie, W.J. \& Kolodinsky, R.W., 2003, 'Nonprofit organization financial performance measurement: An evaluation of new and existing financial performance measures', Nonprofit Management and Leadership 13(4), 367-381. https://doi. org/10.1002/nml.5

Robinson, T.R., Van Greuning, H., Henry, E. \& Broihahn, M.A., 2009, International financial statement analysis, Wiley, Hoboken.

Ryan, C. \& Irvine, H., 2012, 'Not-for-profit ratios for financial resilience and internal accountability: A study of Australian international aid organisations' Australian Accounting Review 22(2), 177-194. https://doi.org/10.1111/j.18352561.2012.00163.x

Sehoole, M.T.C., 2005, 'The politics of mergers in higher education in South Africa', Higher Education 50(1), 159-179. https://doi.org/10.1007/s10734-004-6357-x
South Africa (Republic), 1997, Higher Education Act (Act 101 of 1997, as amended), Government Printer, Pretoria.

South Africa (Republic), 2002, Standard Institutional Statute: Schedule to Higher Education Act, Government Printer, Pretoria.

South Africa (Republic), 2007, Regulations for annual reporting by public higher education institutions, Government Printer, Pretoria.

South Africa (Republic), 2014, Regulations for annual reporting by public higher education institutions, Government Printer, Pretoria.

Stahl, G.K. \& Voigt, A., 2008, 'Do cultural differences matter in mergers and acquisitions? A tentative model and examination', Organization Science 19(1), 160-176. https://doi.org/10.1287/orsc.1070.0270

Stewart, S.D., Piros, C.D. \& Heisler, J.C., 2011, Running money: Professional portfolio management, McGraw-Hill, New York.

Talib, A. A., 2003, 'The offspring of new public management in English universities', Public Management Review 5(4), 573-583. https://doi.org/10.1080/1471903032 000178590

Tinkelman, D. \& Donabedian, B., 2007, 'Street lamps, alleys, ratio analysis, and nonprofit organizations', Nonprofit Management and Leadership 18(1), 5-18. https://doi.org/10.1002/nml.168

Tinkelman, D. \& Donabedian, B., 2009, 'Decomposing the elements of nonprofit organizational performance', Research in Governmental and Nonprofit Accounting 12(1), 75-98.

Trussel, J.M., 2002, 'Revisiting the prediction of financial vulnerability', Nonprofit Management and Leadership 13(1), 17-31. https://doi.org/10.1002/nml.13103

Trussel, J.M. \& Greenlee, J.S., 2004, 'A financial rating system for charitable nonprofit organizations', Research in Governmental and Nonprofit Accounting 11, 93-116.

Trussel, J.M. \& Parsons, L.M., 2008, 'Financial reporting factors affecting donations to charitable organizations', Advances in Accounting 23, 263-285. https://doi.org/ 10.1016/S0884-0741(04)11005-7

Tschampion, R.C., Siegel, L.B., Takahashi, D.J. \& Maginn, J.L., 2012, 'Managing institutional portfolios', in CFA Institute (ed.), Behavioral finance, individua investors, and institutional investors, pp. 395-466, CFA Institute, Charlottesville.

Tuckman, H.P., \& Chang, C.F., 1991, 'A methodology for measuring the financial vulnerability of charitable non-profit organizations', Nonprofit and Voluntary Sector Quarterly 20(4), 445-460. https://doi.org/10.1177/z08997640910200040

Wangenge-Ouma, G., 2012, 'Tuition fees and the challenge of making higher education a popular commodity in South Africa', Higher Education 64(6), 831-844. https://doi.org/10.1007/s10734-012-9531-6

Watkins, A.L., 2000, 'Hospital financial ratio classification patterns revisited: Upon considering nonfinancial information', Journal of Accounting and Public Policy 19(1), 73-95. https://doi.org/10.1016/S0278-4254(99)00025-3

Weisbrod, B.A., Ballou, J.P. \& Asch, E.D., 2008, Mission and money: Understanding the university, Cambridge University Press, New York.

White, G.I., Sondhi, A.C. \& Fried, D., 2003, The analysis and use of financial statements, Wiley, Hoboken, NJ.

Whittington, G., 2008, 'Fair value and the IASB/FASB conceptual framework project: An alternate view', Abacus 44(2), 139-168. https://doi.org/10.1111/j.1467-6281. 2008.00255.x

Wyngaard, A. \& Kapp, C., 2004, 'Rethinking and reimagining mergers in further and higher education: A human perspective', South African Journal of Higher Education 18(1), 185-201. https://doi.org/10.4314/sajhe.v18i1.25437

Zeller, T.L., Stanko, B.B. \& Cleverley, W.O., 1996, 'A revised classification pattern of hospital financial ratios', Journal of Accounting and Public Policy 15(2), 161-182. https://doi.org/10.1016/0278-4254(96)00014-2 


\section{Appendix 1}

TABLE 1-A1: The South African public universities 2007-2016. $\dagger$

\begin{tabular}{|c|c|c|c|c|}
\hline Abbreviation & Institution name & Campus location & Students: & Revenues $\S$ \\
\hline CPUT & Cape Peninsula University of Technology & Cape Town & 34455 & 2255 \\
\hline CUT & Central University of Technology & Bloemfontein and Welkom & 15708 & 903 \\
\hline DUT & Durban University of Technology & Durban & 28377 & 1821 \\
\hline MUT & Mangosuthu University of Technology & Durban & 11588 & 655 \\
\hline NMUף & Nelson Mandela University & Port Elizabeth & 27780 & 2419 \\
\hline NWU & North-West University & Mafikeng and Potchefstroom & 63395 & 3916 \\
\hline SU & Stellenbosch University & Stellenbosch & 30161 & 5021 \\
\hline TUT & Tshwane University of Technology & Tshwane & 58901 & 3269 \\
\hline UCT & University of Cape Town & Cape Town & 29232 & 6165 \\
\hline UFH & University of Fort Hare & Alice and East London & 13831 & 1338 \\
\hline UFS & University of the Free State & Bloemfontein & 36269 & 2674 \\
\hline UJ & University of Johannesburg & Johannesburg & 51795 & 4123 \\
\hline UKZN & University of KwaZulu-Natal & Durban, Pietermaritzburg, et al. & 46472 & 4363 \\
\hline UNISAT† & University of South Africa & Pretoria & 299324 & 6910 \\
\hline UP & University of Pretoria & Pretoria & 53232 & 6383 \\
\hline UV & University of Venda & Thohoyandou & 15237 & 1062 \\
\hline Wits & University of the Witwatersrand & Johannesburg & 37448 & 6436 \\
\hline UWC & University of the Western Cape & Cape Town & 21796 & 2433 \\
\hline UZ & University of Zululand & Richards Bay & 17662 & 1073 \\
\hline VUT & Vaal University of Technology & Vanderbijlpark, Secunda, et al. & 19241 & 1201 \\
\hline WSU & Walter Sisulu University & Mthatha, Butterworth, et al. & 28581 & 1667 \\
\hline
\end{tabular}

Note: Please see the full reference list of the article, Bunting, M., 2020, 'Dimensions and indicators of non-profit financial condition: Evidence from South African public universities', South African Journal of Economic and Management Sciences 23(1), a2974. https://doi.org/10.4102/sajems.v23i1.2974, for more information.

$\dagger$, Excludes three newer universities: Sol Plaatje University (established 2013), University of Mpumulanga (2013), and Sefako Makgatho Health Sciences University (2015); $\$$, source from Department of Higher Education and Training (2018). Head count enrolments in 2016; §, source from this study. Total revenues for 2016, in millions of South African rand; 9 , formerly known as Nelson Mandela Metropolitan University; $\uparrow$, distance education provider. All other universities are residential. 